\title{
EVALUATION OF PESTE DES PETITS RUMINANTS (PPR) CELL CULTURE VACCINE IN GOATS AND SHEEP IN INDIA
}

\author{
S. Baksi", H. Dave, N. Rao, P. Malsaria, M. Khan and P. Chauhan
}

Hester Biosciences Limited, Ahmedabad - 380006, Gujarat, India.

\begin{abstract}
Peste des Petits Ruminants (PPR) is a highly contagious viral disease of ruminants. The disease has high impact on small ruminants market, especially in Africa and Middle East. India has a large population of sheep and goats, having significant part in world ruminant population. Prevention and control programs by vaccines are necessary parts of ruminants business. PPR vaccines are successfully used by small and large farmers in various parts of India. Researches have been done to investigate the efficacy of PPR vaccines on sheep and goats, but few data are available on sero-conversion in the bodies. In present study, sheep and goats were vaccinated with Sungri/96 strain and serum collection was done up to one year. Antibodies levels were measured with competitive ELISA. Antibody levels reached to protective levels within 21 days of vaccination, which continued up to one year. Sheep responded to vaccine slightly better than goats. Further studies are required to investigate total duration of protection by PPR vaccine in small ruminants.
\end{abstract}

Keywords: PPR, India, antibody, vaccine, immune

\section{INTRODUCTION}

Peste des Petits Ruminants (PPR) disease is a viral disease of sheep and goats having significant economic concern all over the world. PPR virus (PPRV) is a member of the genus Morbilivirus of family Paramyxoviridae. The disease has 3-6 days of incubation period, followed by high fever, occulonasal discharge, pneumonia, stomatitis and inflammation of gastrointestinal tract leading to severe diarrhoea followed by death or recovery (Zahur et al., 2008; Sen et al., 2010; Balamurugan et al., 2014). The virus spread through close contact between infected and healthy animals. Primarily it is transmitted through respiratory route. PPR disease was first recorded in West Africa in 1940s by Gargadennec and Lalanne (1942). Prevalence was also found in other parts of Africa and Middle East (Rahim et al., 2010; Aamer et al., 2014, Banyard et al., 2014). The disease was reported in India in 1990s, first in southern and then northern part (Shaila et al., 1996; Kumar et al., 1999, Taylor et al., 2001). PPR has huge economic concern worldwide as well as India (Muthuchelvan et al., 2015). The morbidity of the disease may be up to $100 \%$ and severe fatality in acute cases (OIE, 2013). India has a small ruminant population of 200 million and estimates show that PPR causes economic losses up to US\$ 39 every year in India. In past years, there has been several outbreaks of PPR recorded in India (Singh, 2011). Controlling PPR seems to be comparatively easier than other economically important fatal viral diseases like foot and mouth disease and bluetongue. Effective vaccines are also available to control the prevalence of the disease. Several researches reveal that PPR vaccines of different strains have protected small ruminants like sheep and goats (Awa et al., 2003; Rashid et al., 2010; Aamer et al., 2014). Most researchers have preferred ELISA method to detect presence of specific antibodies against PPRV. It is easy, rapid, reliable and less time consuming method for the experiment. Looking at present scenario of PPR disease in India and control programs in the urban as well as rural animal husbandries, present study was designed to investigate specific antibody response of PPR vaccine of Indian market on sheep and goats.

*Corresponding e-mail address: drsbaksi.vm@gmail.com 
Surajit Baksi and others

\section{MATERIALS AND METHODS}

\section{Grouping and rearing of goats}

45 healthy Jamunapuri goats and 45 healthy Marwari sheep of one year of age were selected for the study and divided into four groups:

Group 1: 35 goats (vaccinated with PPR live vaccine (Sungri/96 strain), procured from Hester Biosciences Limited, India)

Group 2: 10 goats (unvaccinated control)

Group 3: 35 sheep (vaccinated with PPR live vaccine (Sungri/96 strain), procured from Hester Biosciences Limited, India)

Group 4: 10 sheep (unvaccinated control)

Vaccinated goats and sheep from group 1 and 3 were kept separately at Merda-Adraj village, Gujarat, India. Unvaccinated goats and sheep from group 2 and 4 were kept at Jetpura village, Gujarat, India. All animals were subjected to free supply of feed and water and observed daily throughout study.

\section{Vaccination, blood collection and testing}

Animals from group 1 and 3 were vaccinated subcutaneously in cool atmosphere with one dose of PPR live vaccine (Sungri/96 strain), procured from Hester Biosciences Limited, India. Blood samples were collected from 10 animals/ group at 0,7,14,21,28,35,42,49 and 56 days; followed by 3, 4, 5, 6, 7, 8, 9, 10, 11 and 12 months. Serum was separated and stored at $-20{ }^{\circ} \mathrm{C}$.

All sera samples were subjected to ELISA test using ELISA kit (ID.vet innovative diagnostics, France) at Hester Biosciences Limited, Anand laboratory. The ELISA was run after collection of all the blood samples and it was run as per the manufacturer's protocol and instruction. Before use, all the samples and reagents were allowed to room temperature and homogenized by gentle mixing. $25 \mu 1$ of dilution buffer was added to each well. $25 \mu \mathrm{l}$ of the positive control was added to wells A1 and B1. $25 \mu 1$ of the negative control was added to wells C1 and D1. $25 \mu$ l of each sample to be tested was added to the remaining wells. Plate was incubated for 45 min at 37 ${ }^{\circ} \mathrm{C}$. Each well was washed with $300 \mu \mathrm{l}$ wash solution 3 times. Conjugate $1 \mathrm{X}$ was prepared by diluting $10 \mathrm{X}$ conjugate to 10 times with dilution buffer. Further, $100 \mu \mathrm{l} 1 \mathrm{X}$ conjugate was added to each well. Plate was incubated for $30 \mathrm{~min}$ at $21{ }^{\circ} \mathrm{C}$. Each well was washed with $300 \mu \mathrm{l}$ wash solution 3 times. $100 \mu 1$ of substrate solution to each well was added. Again it was incubated for $15 \mathrm{~min}$. at $21^{\circ} \mathrm{C}$. Finally, $100 \mu \mathrm{l}$ of stop solution was added to each well to end the reaction. Then O.D. at $450 \mathrm{~nm}$ was read. The unit of measurement was S/N percentage. S/N percentage of $\leq 50 \%$ was considered positive, while that of $50-60 \%$ was considered doubtful. $>60 \% \mathrm{~S} / \mathrm{N}$ percentage was considered negative for presence of antibodies against PPRV. All the results were recorded as Mean \pm S.E.M.

\section{Data analysis}

All data were entered into Microsoft Office Excel Worksheet (2013, Microsoft Corporation). The data were analyzed by single factor - analysis of variance method and $\mathrm{p}<0.05$ was considered as significant difference between the groups.

\section{RESULTS}

The initial antibody titres of goats were $229.0 \pm 3.2$ (Group 1) and $238.3 \pm 6.4$ (Group 2). The initial titres of sheep were $245.1 \pm 7.8$ (Group 3) and $253.9 \pm 8.4$ (Group 4). S/N percentage decreased gradually in both vaccinated groups (Group 1 and 3). Vaccinated goats' (Group 1) S/N percentage was decreased drastically and significantly up to 21 days $(24.6 \pm 1.3)$, which continued to change at smaller differences thereafter up to one year. Same scenario of results was observed in the results of vaccinated sheep also (Group 3) (Figure 1). It was also observed that there was slightly less $\mathrm{S} / \mathrm{N} \%$ in vaccinated sheep as compared vaccinated goats (Figure 2). There was consistent antibody level observed in both unvaccinated groups of goats and sheep (Group 2 and 4 ) throughout the year. 
PPR vaccine efficacy in India

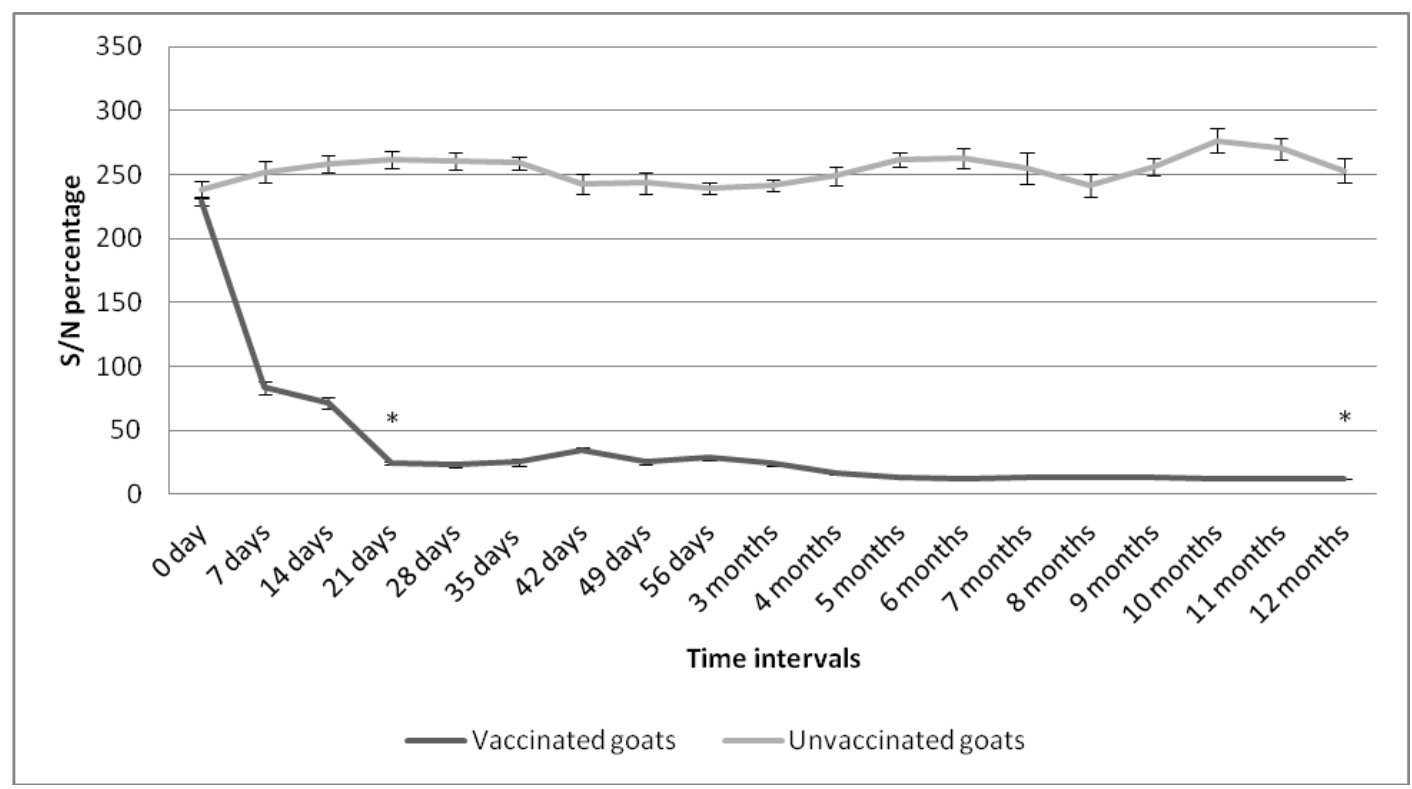

Figure 1. S/N percentage of group 1 and 2 (Vaccinated and unvaccinated goats)

The data are experssed as mean \pm SEM

$* \mathrm{p}<0.05$, significantly different as compared to 0 days

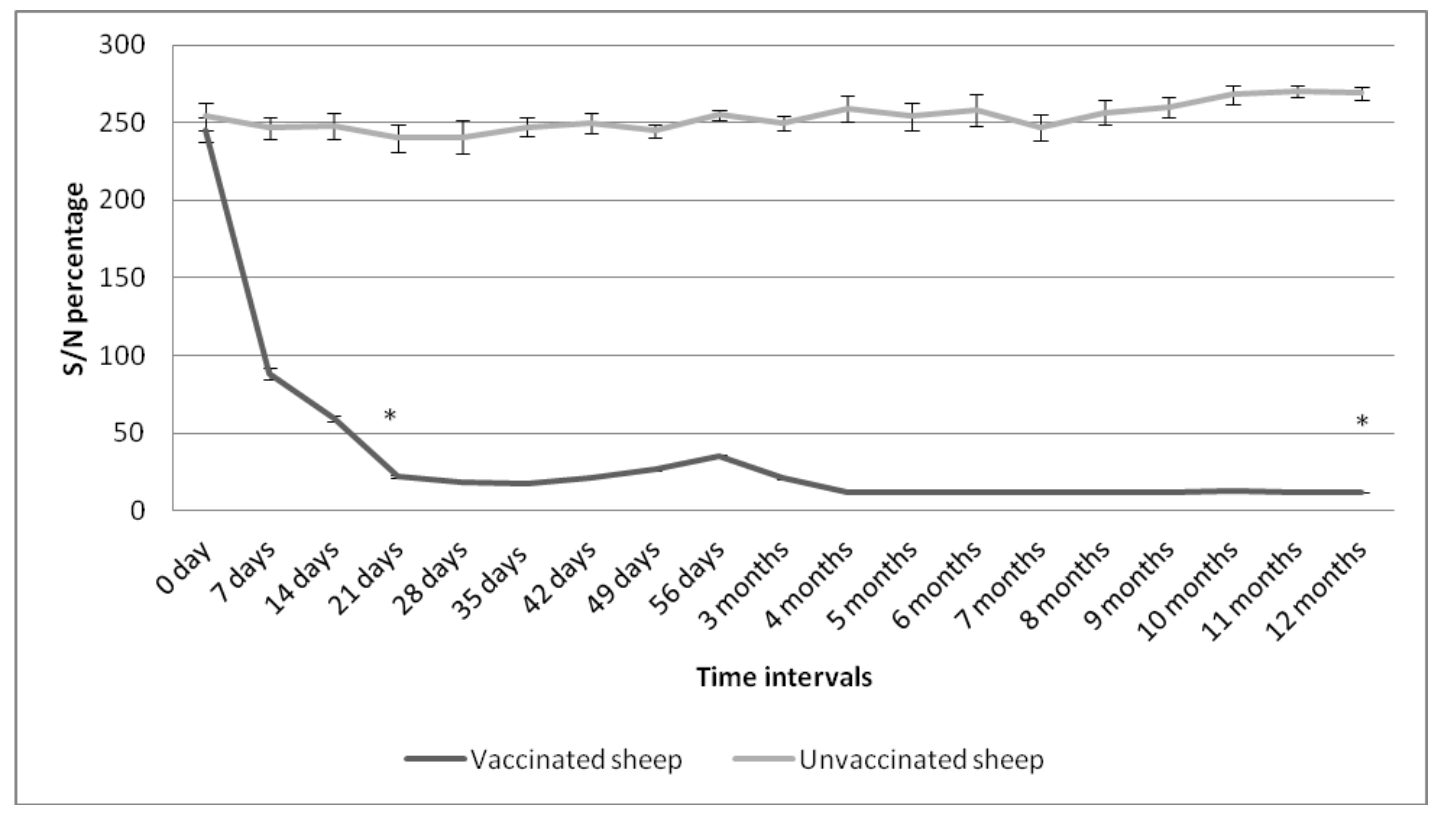

Figure 2. S/N percentage of group 3 and 4 (Vaccinated and unvaccinated sheep) The data are experssed as mean \pm SEM

$* \mathrm{p}<0.05$, significantly different as compared to 0 days 


\section{DISCUSSION}

In present study, unit of measurement was $\mathrm{S} / \mathrm{N}$ percentage, using calculation referred by manufacturer of ELISA kit. Rashid et al. (2010) reported the antibody levels with percentage inhibition values, which was considered directly proportional to the antibody levels. In present study, it was assumed that lesser the S/N \%, higher the antibody levels. Before vaccination, blood was withdrawn from sheep and goats and screening was done for the presence of antibodies, which was found negative, as all samples had $>200 \% \mathrm{~S} / \mathrm{N}$ ratio. After vaccination, within 7 days only, $\mathrm{S} / \mathrm{N} \%$ decreased drastically to around 80 in both the species. But, the titre reached to protective level $(<50 \%)$ at 21 days interval after vaccination. Similar observation was reported by Rashid et al., 2010, where \% inhibition reached to >50 in both vaccinated species i.e., sheep and goat. Other researchers also found similar results after vaccination to sheep and goats (Chaudhary et al., 2009; Gelagay et al., 2012; Fakri et al., 2015). After 21 days of vaccination, the titre remained protective up to the end of the study in sheep and goats as well (Rashid et al., 2010; Aamer et al., 2014; Zeidan et al., 2016). It was also observed that sheep responded better to the vaccine than goats, but the data were not significantly different. Further investigations can be done to understand the protective behavior of the vaccine extended than one year.

\section{REFERENCES}

1. Aamer BZ, Hamid I, Aman U, Muhammad A, Asma L, Riasat WU, Umer F, Muhammad HS, Muhammad J, Giancarlo F, Manzoor H and Munir MA (2014). Peste des Petits Ruminants vaccine (Nigerian strain 75/1) confers protection for at least 3 years in sheep and goats. Journal of Biosciences and Medicines 2: 27-33.

2. Awa DN, Andre N, Eonore E, Daouda Y and Aboubakar N (2003). Post vaccination and colostral peste des petits ruminants antibody dynamics in research flocks of Kirdi goats and Fulbe sheep of North Cameroon. Jean-Yves J, Lamine SB, Christian F. Cirad - Prasac. Preventive Veterinary Medicine 55:265-271.

3. Balamurugan V, Hemadri D, Gajendragad MR, Singh RK and Rahman H (2014). Diagnosis and control of peste des petits ruminants: a comprehensive review. Virus Disease 25:39-56.

4. Banyard AC, Parıda S, Batten C, Oura C, Kwiatek O and libeau G (2010). Global distribution of peste des petits ruminants virus and prospects for improved diagnosis and control. Journal of General Virology 91:2885-2897.

5. Chaudhary S, Pandey K, Singh R, Verma P and Gupta P (2009). A vero cell derived combined vaccine against sheep pox and peste des petits ruminants for sheep. Vaccine 27: 2548-2553.

6. Fakri F, Ghazal F, Daouam S, Elarkam A, Douieb L, Tadlaoui K, Fassi-Fihri O and Elharrak M (2015). Field application of a combined vaccine against Peste des Petits Ruminants and sheep pox. Journal of Vaccines and Vaccination 6:6.

7. Gargadennec L and Lalanne A (1942). La peste des petits ruminants. Bulletin des Services Zoo Techniques et des. Epizzoties de l'Afrique Occidentale Francaise 5:15-21.

8. Gelagay A, Nigussu F, Shiferaw J, Gedlu M, Teshale S and Negussie H (2012). Study on immunogenicity of combined sheep and goat pox and peste des petits ruminants vaccines in small ruminants in Ethiopia. African Journal of Microbiology Research 6:7212-7217.

9. Kumar GS, Rathore BS and Mehrotra ML (1999). Epidemiological observations on Peste des Petits Ruminants in north India. Indian Journal of Animal Sciences 69:365-368.

10. Muthuchelvan D, Rajak KK, Ramakrishnan MA, Choudhary D, Bhadouriya S, Saravanan P, Pandey AB and Singh RK (2015). Peste-des-petits-ruminants: An Indian perspective. Advances in Animal and Veterinary Science 3: 422-429.

11. Peste Des Petits Ruminants (Infection with Peste Des Petits Ruminants virus). Chapter 2.7.10. OIE Terrestrial Manual, 2013.

12. Rahim IHA, Sharawi SSA, Barakat MR and Nahas EM El (2010). An outbreak of Peste des Petits Ruminants in migratory flocks of sheep and goats in Egypt in 2006. Revue scientifique et technique (International Office of Epizootics) 29:655-662.

13. Rashid A, Azhar H and Muhammad A (2010). Evaluation of Peste des Petits Ruminants cell culture vaccine in sheep and goats in Pakistan. Veterinaria Italiana 46:315-318.

14. Sen A, Saravanan P, Balamurugan V, Rajak KK, Sudhakar SB, Bhanuprakash V, Parida S and Singh RK (2010). Vaccines against peste des petits ruminants virus. Expert Review: Vaccines 9:785-796. 
15. Shaila MS, Shamaki D, Forsyth MA, Diallo A, Goatley L, Kitching RP and Barrett T (1996). Geographic distribution and epidemiology of peste des petits ruminants viruses. Virus Research 43:149-153.

16. Singh RP (2011). Control strategies for peste des petits ruminants in small ruminants of India. Revue Scientifique et Technique (International Office of Epizootics) 30: 879-887.

17. Taylor WP, Diallo A, Gopalakrishna S, Sreeramalu P, Wilsmore AJ, Nanda YP, Libeau G, Rajasekhar M and Mukhopadhyay AK (2001). Peste des Petits Ruminants has been widely present in southern India since, if not before, the late 1980s. Preventive Veterinary Medicine 52: 305-312.

18. Zahur AB, Irshad H, Hussain M, Ullah A, Jahangir M, Khan MQ and Farooq MS (2008). The epidemiology of Peste des Petits Ruminants in Pakistan. Revue scientifique et technique (International Office of Epizootics) 27: 877-884.

19. Zeidan S, Namaa AM, Hanan MS, Zawahry EL, Saad MA, Nakhla E, Afaf AW, Abeer AT, EDakhly AT (2016). Preliminary study for preparation of combined attenuated vaccine against sheep pox and ppr viruses. International Journal of Advanced Research 4:212-219. 